\title{
Monthly Status Update - December 2016 \\ Afghan Civilian Assistance Program (ACAP III)
}

\section{Highlights:}

- Funded and facilitated provision of one of the first electric hands in Afghanistan to a double amputee. The procedure was successful and the beneficiary has been able to resume daily activities, improving his quality of life.

- Held 42 immediate assistance distribution events in various parts of the country. 352 immediate assistance packages were delivered reaching 3,486 beneficiaries (1,732 male and 1,754 female).

- Enrolled 407 victims (301 male and 106 female) and 689 family members of victims ( 347 male and 342 female) in psychosocial counselling. Counselling is ongoing for 768 beneficiaries (312 victims, 456 family members).

- Provided physical therapy visits and referrals to 400 beneficiaries (302 males and 98 females).

- Delivered 60 economic reintegration assistance packages

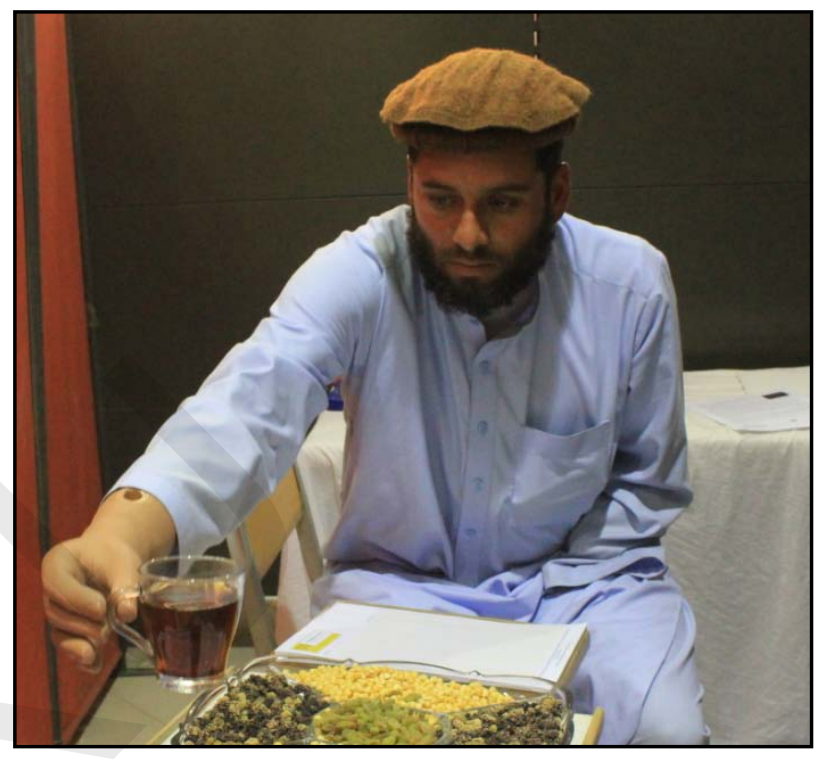

A double amputee fitted with an electric hand through support from ACAP III tests the use of the hand. @UNMAS tailored to victim's and families' needs.

- $\quad$ Supported the Ministry of Public Health (MoPH) in conducting monitoring visits for ACAP III psychosocial services in Kabul. Discussed an action plan for expanding MoPH's monitoring of ACAP III psychosocial services throughout the country.

- Provided technical support and guidance for an event observing the International Day of Persons with Disabilities on 3 December. The Chief Executive of National Unity Government, Dr. Abdullah Abdullah attended and gave a speech. The event received wide national media coverage.

\section{Issues:}

- No issues to report, operations are continuing as usual.

\section{Planned activities for next month:}

- Complete a review of planned program activities for $2017-2018$.

- Engage an implementing partner for the implementation of the National Disability Survey.

- Sign letters of agreement with two partner ministries (MoPH and MoLSAMD) for the implementation of ministry related ACAP III activities. 